\title{
Contracting out of health services improves service utilization and satisfaction: evidence from rural districts of Pakistan
}

Imran Naeem Naeem ( $\sim$ imran.naeem2009@gmail.com )

Aga Khan University https://orcid.org/0000-0002-9487-1303

\section{Zafar Fatmi}

Aga Khan University

\section{Research}

Keywords: Contracting out, Non-state providers, Pakistan, Rural setting, public health facilities

Posted Date: March 4th, 2020

DOI: https://doi.org/10.21203/rs.3.rs-16031/v1

License: (c) (1) This work is licensed under a Creative Commons Attribution 4.0 International License.

Read Full License 


\section{Abstract}

Background Contracting out of health services to non-state providers has been widely used in developing countries including Pakistan. Based on three years' experience of contracting out primary and secondary health services, this paper presents findings of third party evaluation of health services from two rural districts of Sindh Pakistan. Methods This was a baseline vs end-line cross sectional assessment of thirteen primary and secondary healthcare facilities from two rural districts (Thatta and Sujawal) of Sindh province that were contracted out in 2016 to a national non-governmental organization. Healthcare facilities included: 8 rural health centres, 4 taluka headquarter hospitals and 1 district headquarter hospital. District health information system was used to extract three years $(2016-2019)$ data on key performance indicators (KPIs) as agreed in contract. We conducted record review related to human resource and budget and in-depth interviews with health managers. Health facility assessment survey and client satisfaction exit interviews were also conducted. Results KPIs showed significant improvement in service provision from baseline. General outpatient department (OPD) (33\%), specialist OPD (91\%), accident/emergency consultations (106\%), in-patient admissions ( $\geq 100 \%)$ alongside diagnostic/laboratory service utilization (86\%) increased substantially. Facility based deliveries (37\%), and major (99\%) and minor (172\%) surgeries also showed significant increase. Preventive services (maternal tetanus toxoid, child vaccination) showed modest improvement (4-19\%) in the district (overall) but slight decline in some healthcare facilities. Slight improvement in specialist workforce care was noticed, however challenges related to staff retention persisted. Adequate supplies and equipment were available except radiology services. Most healthcare facilities were also in need of repair. Delayed and partial release of funds by government was a major barrier. Lack of coordination among different stakeholders delivering healthcare in the district was also noted. Majority of clients $(60 \%)$ were satisfied with service delivery but unavailability of medicine was their main concern. Conclusions Contracting out has the potential to improve service utilization. Autonomy over budget allocation and utilization, appointment of all cadre of staff, and improved coordination among all stakeholders is required to improve service delivery. Quality of care and the longer term health outcomes need further evaluation.

\section{Background}

Improvement in health service utilization is the first step towards Universal Health Coverage. Contracting out of health services has been mushrooming as a popular modality of delivering health services in many countries particularly in remote rural settings (1). Contracting out governs the utilization of public funds through a formal agreement between government as financier and a non-state provider (NSP) such as a non-governmental organization (NGO) as service provider on behalf of government. Agreement is made for mutually agreed set of services, usually for a defined period and geographic area, where services are required (2-4).

Contracting out has been argued to be beneficial in circumstances where governments lack management capacity and system level issues prevent governments from timely and effective utilization of resources (5). It may also free-up government to play its strategic role of stewardship with a focus on better 
planning and monitoring (6). On the other hand, private providers will have better determination, technical capacity (5) and focused approach towards the measureable health outcomes (7). It also potentially devolve the decision making circumventing the interference from bureaucracy (6).

Contracting out approach has been used in war affected countries such as Afghanistan to quickly roll out health interventions, in poorer countries such as Cambodia to ensure availability of services and in relatively stable countries like Bangladesh, India, Iran and Pakistan to improve efficiency of health service delivery (8).

Pakistan's health system has also undergone an extensive contracting out during past 15 years with several of the primary and secondary healthcare facilities contracted out to NSPs $(9,10)$. Sindh health department, through setting up a public-private partnership (PPP) node, has done extensive contracting out of most of the province's primary and secondary healthcare facilities to several NGOs (9). Following a nationwide contracting out initiative - People's Primary Healthcare Initiative (PPHI) - of primary healthcare facilities i.e. basic health units (BHUs) in 2005, progressively more primary and secondary healthcare facilities have been contracted out to multiple NGOs including in Sindh province.

While this expansion of contracting out initiatives in Sindh province is important to health system, there is very little evidence available regarding their impact on health services. Present study is an independent evaluation that aims to: i) determine the improvement from baseline in health services, if any, of the contracted out primary and secondary healthcare facilities in two rural districts (Thatta and Sujawal) of Sindh province against key performance indicators (KPIs), ii) explore perceptions of health managers regarding contracting out and its facilitator and barriers in the two districts; iii) determine experience of patients/clients regarding availability and quality of health services in contracted out healthcare facilities.

\section{Methods}

\section{Healthcare system in Sindh, Pakistan}

Sind province has an extensive network of public and private healthcare providers. Public sector comprises of primary and secondary healthcare facilities including $757 \mathrm{BHUs}, 125$ Rural health centers (RHCs) (11) and 98 secondary and tertiary care hospitals $(12,13)$. Out of these, 51 BHUs, 8 RHCs, 4 taluka headquarter hospitals (THQHs) and 1 district headquarter hospital (DHQH) are located in the two districts of Sindh i.e. Thatta and Sujawal. Two national level NGOs were awarded the contract for managing public sector healthcare facilities i.e. BHUs were managed by one, while RHCs and secondary hospitals were contracted out to another NGO.

\section{Authorities and deliverables of agreement}

The healthcare facilities evaluated had been contracted out to a national NGO since 2016. The contractual agreement included defined set of KPIs (appendix I). Authoritative powers arising as a result of contract included: i) financial management without control over amount and release of budget which 
was solely in the domain of PPP node; ii) human resource management including hiring, firing and transfers of contractual staff; iii) posted government staff made available but without authority for transfer or termination; iii) use and management of building infrastructure and equipment.

\section{Study design and study setting}

Till recently (2013) Thatta was a single district until it was split into two separate districts namely Thatta and Sujawal. Both districts are predominantly rural and have a population of approximately 1 million each (14). Health indicators are amongst the lowest in the country: maternal mortality ratio (MMR) and neonatal mortality ratio (NMR) i.e. MMR of as high as 313/100, 000 live births compared to national estimate of 178/100, 000 live births and NMR of 50/1000 live births against the national estimate of 41.95/1000 live births (15-17) has been reported.

We evaluated the program using pre-post design (baseline vs end-line) using a cross-sectional survey, observations and qualitative interviews. All (thirteen) primary and secondary healthcare facilities from two rural districts (Thatta and Sujawal) of Sindh province were evaluated. Healthcare facilities included: 8 RHCs, 4 THQHs and 1 DHQH (appendix II).

\section{Review of district health information system data and agreement}

District health information system (DHIS) was used to extract three years (2016 - 2019) data on KPIs as defined in contracting out agreement between PPP node and NGO. Thorough review of service agreement, records related to human resource and budget was done. Validation of data was performed by making visits to healthcare facilities and conducting meetings with concerned personnel.

\section{Health facility assessment}

Validated tool(18) was adapted and used to conduct health facility assessment. The purpose was to assess current status of human resource, drugs, supplies and equipment and infrastructure.

\section{In-depth interviews with health managers}

Using semi-structured guide, ten in-depth interviews (IDIs) were conducted from health managers of health facilities and program managers to understand the barriers and facilitators of contracting out and its impact on health service utilization.

\section{Client satisfaction exit interviews}

The study adapted and used validated tool (19) to conduct client satisfaction exit interview with 95 participants (5-10 from each health facility) to determine experience of clients regarding availability and quality of service delivery.

\section{Ethical considerations}


Ethical approval for this study was obtained from the Ethics Review Committee of the Aga Khan University Karachi. Permission was sought from program managers and in-charges of healthcare facilities and informed written and verbal consent was obtained from all interviewees. In order to anonymize the respondents, codes were assigned and password access was used to restrict access to data.

\section{Data management and analysis}

Field editing of the data collection forms was done. After editing, data was entered and analysed into Microsoft excel 2016. Descriptive statistics were run and proportion were calculated for categorical variables. For qualitative analysis, data from IDIs was transcribed and translated from local (Sindhi) language to English. All transcripts were read through and brief notes were made. Following manual content analysis, responses were grouped and compared. Similar responses were merged and the results are presented as emergent themes. The findings from qualitative and quantitative components were validated through triangulation.

\section{Results}

There was an overall improvement in utilization of health services from the baseline in the contracted out healthcare facilities. Moreover, improvements were greater in Thatta compared to Sujawal district in all KPIs. An improvement of $33 \%$ was observed in out-patient department (OPD) consultations with noticeable progress of $91 \%$ in specialist consultations and $106 \%$ in accident and emergency consultations from the baseline. General OPD consultations, however, increased only slightly (3\%). Inpatient admissions also showed upward trend (figure 1). The volume of OPD consultations was inconsistent. A noticeable decline in number of consultations was observed during second quarter of every year (the end of fiscal year).

Facility based deliveries, both vaginal and caesarean section, increased $36 \%$ and $49 \%$ respectively with an overall improvement of $37 \%$. However, most of the caesarean section were reported from healthcare facilities in Thatta (figure 2). This was consistent with the finding that majority of surgeries both major and minor were also reported from Thatta district (figure 3).

Marked improvement was seen in $1^{\text {st }}$ antenatal care (ANC) visits however there was little improvement in postnatal care (PNC) visits until after two years when PNC visits improved noticeably. There was overall increase of $19 \%$ in proportion of pregnant women receiving $2^{\text {nd }}$ tetanus toxoid vaccine dose. However, the increase was prominent in Thatta while it actually showed a decline in Sujawal (figure 4).

Immunization indicators for children under 1 year of age showed decline as number of children fully immunized, immunized for third dose of pentavalent vaccine and $1^{\text {st }}$ dose of measles vaccine indicated inconsistent and downward trend for the contracting out period (figure 5). 
Overall, healthcare facilities of district Thatta showed greater improvements in utilization of health services compared to those of Sujawal district. Utilization of services at DHQH Thatta, the only hospital in the two district, showed highest utilization of services including OPD, surgeries, laboratory and diagnostic services and maternal health services. Though there was improvement in most services at THQHs of both the districts, THQHs of Sujawal showed decline in immunization and laboratory services (figure 6).

Almost all RHCs showed improvement in OPD consultations, ANC and PNC, but improvement in institutional deliveries was sluggish and immunization services showed declines at majority of RHCs (figure 7).

For assessing bed capacity, drugs, equipment and supplies and infrastructure, there was no baseline data available and hence these were assessed for adequacy through health facility assessment survey.

\section{Bed capacity}

RHCs had beds available to cater to in-patient care for cases such as conducting normal vaginal deliveries, treatment pediatric cases for dehydration and cases of accident and trauma. Among the eight RHCs, the average number of bed capacity was 13, with a minimum of 5 and a maximum of 20 beds. Beds to population ratio however was low in most cases.

Among secondary hospitals, those in Thatta had the highest bed strength compared to Sujawal with 242 beds in DHQH in Thatta. In Sajawal, range of beds in THQHs was minimum of 16 to maximum of 98.

\section{Availability of drugs}

Though most of the essential drugs were present at majority of the RHCs, essential anticonvulsant and anti-epileptics were found out of stock on all RHCs. Second most important group of drugs found deficient was anti-diabetics. For all the THQHs in both districts, most of the essential drugs were in stock, while antidotes, anti-allergic, respiratory and eye and ear medications were out of stock at the time of the survey.

\section{Availability of equipment and supplies}

General medical equipment and supplies were available at most RHCs, but availability of radiology equipment such as x-ray and ultrasound machines were non-existent in some RHCs. Though all secondary hospitals were slightly short on supply of equipment a functional operation theater was available at three of the five hospitals.

\section{Infrastructure}

There was a need to bring improvements in infrastructure and 9 out of total 13 healthcare facilities were in need of repair. Similar number of facilities had separate latrines for patients but these needed repair. Almost half of healthcare facilities had a proper waste disposal mechanism but an equal number lacked pit incinerators. Non-availability of safe drinking water was a major finding as only 5 of the 13 facilities 
had potable water available. Unavailability of water also affecting functioning of latrines. Staff housing at all the facilities was in need of repair. DHQH Thatta was the hospital that received most attention in terms of infrastructure improvement.

\section{Situation of health workforce}

Overall, staffing situation improved significantly in both the districts. Recruitment for all cadres such as specialists, general doctors, paramedics and support staff were done against vacant positions (figure 8). However, shortage of human resource still persisted at secondary hospital and more so in healthcare facilities of Sujawal district. Similarly, number of vaccinators at all RHCs, though appropriate against sanction positions, was not adequate given low immunization coverage and scattered geography of population.

\section{Budgetary issues}

For all the three fiscal years, not only that there was a delay in release of budget, but the amount of budget released was lower than total of the committed amount. In $2016-17,72 \%$ of the committed amount was released. This was even lower in subsequent years i.e. $64 \%$ and $58 \%$ for $2017-18$ and 2018 - 19, respectively. When broken down by line items, human resource budget released for each fiscal year was even lower i.e. $34 \%, 66 \%$ and 57\% for years 2016 - 17, 2017 - 18 and 2018 - 19, respectively.

\section{Perceptions of program managers regarding contracting out}

\section{Delayed and partial release of funds}

Delayed and partial release of budget was stated as a major challenge in maintaining day to day operations and paying timely salary to employed staff. This issue that started from day one kept escalating every year and resulted in increased staff turnover. Employees that already were affected by job insecurity due to contractual nature of job were not able to continue given delays in salaries. Thus finding and retaining qualified human resource was constant ordeal.

\section{Fragmented health system}

Extensive contracting out of healthcare facilities has led to improved utilisation of health services. But contracting of healthcare facilities to multiple NSPs within the same district has not been accompanied by concurrent measure to ensure coordination. Both in Thatta and Sujawal districts, BHUs were contracted out to one NGO, RHCs and secondary hospitals had been handed over to another NSP and the vertical programs such as immunization and lady health workers (LHW) program fell under the domain of government's district health office (DHO). While there was no mechanism of reporting between NSPs and DHO office, communication channels between NSPs were also lacking. 
Water and sanitation was a major concern for both the districts in general and also affected the functioning of healthcare facilities. Several of the healthcare facilities were without continuous supply of water also rendering latrines unusable. Unavailability of water also posed threat to health of patients and healthcare staff as maintaining cleanliness through practices such as hand washing was not possible in absence of water. Lack of electricity affected vaccine storage at optimal temperatures and in absence of backup generator led to interruption of services such as operative and trauma care at secondary hospitals.

\section{Remoteness of healthcare facilities}

Scattered geography of the region also created difficulties in reaching to some healthcare facilities both for staff to reach on time and for patients to get timely healthcare. One of the healthcare facility located along the main highway received accident and trauma cases. Despite being the only facility in the vicinity, there was no provision for medico-legal officer (MLO), hence it had to turn away the MLO cases to a distant secondary hospital. To add to the misery, weak or absent mobile networks created hurdles in communication from and to these healthcare facilities.

\section{Findings from client exit interviews}

More than $60 \%$ clients said that they were satisfied with services at these healthcare facilities. About $50 \%$ clients said they have seen improvement in services whereas $60 \%$ said there have been infrastructure improvements at healthcare facilities in past two years. Availability of medicines at the facilities was a major problem for approximately $64 \%$ of clients and about $34 \%$ were unhappy with the cleanliness of the facilities. About $96 \%$ clients said that they didn't have to pay for availing services from these healthcare facilities (table 1).

\section{Discussion}

The study shows that there was significant increase against baseline in the utilization of health services at contracted out healthcare facilities both secondary hospitals and RHCs. The increase was seen across the range of services including OPD consultation for general, specialist and accident and emergency, ANC, institution based deliveries and PNC visits, general surgery, laboratory and diagnostic services. However, preventive services such as immunization showed inconsistent results with decline at most of the healthcare facilities. Studies from countries such as Malawi (20), India (21) and Cambodia (22) have reported similar results regarding utilization of health services.

Improvements were most notable in maternal health services including ANC and PNC visits and institutional deliveries. Given the severity of the problem and global attention given to maternal health issues, indicators such as ANC and PNC were explicitly stated as KPIs in the service delivery contract. Studies from Malawi (20), India (21) and Cambodia (22) have shown a similar increase in service utilization. Being a priority health issue, it also received attention in health workforce leading to increased 
number of general female doctors and specialist doctors such as gynecologists/obstetricians hence partly explaining the increased service utilisation.

Unexplained delays at the level of bureaucracy prevented timely release of budget. Compounded with partial release, the budget was insufficient to meet the requirements with major impact on staff retention and availability of some essential drugs. Health managers pointed out political interference in hiring and firing of staff prying with staff accountability. Moreover, impact of insufficient budget was evident at the end of each fiscal year (i.e. June), where most of the service utilization indicators showed a downward trend. Studies from countries experimenting with contracting out modalities in health such as Afghanistan and Tanzania have reported political interference as a key challenge for NSPs as they have to deal with local officials, landlords and often members of the parliament $(23,24)$. Political interference caused by state actors makes it difficult to ensure availability and quality of health services with consequent negative impact on the public image of the organization jeopardizing its future.

Lack of control over transfer of government appointed employees resulted in frequent shortage of health workforce in the district as these transfers by the government were done without giving due consideration to human resource needs. Given delayed release of salaries and contractual nature of employees hired by NSP, staff turn over was a persistent challenge. Combined both these issues resulted in work force deficiency as a constant ordeal throughout the contracting out period.

Improvement in immunization compared to other KPIs was meager and rather inconsistent. Despite preventive care being the mandate of primary healthcare facilities, majority of RHCs showed a decline in immunization coverage rates. This is a consistent finding in studies from Malawi and Guatemala that have reported similar pattern $(20,25)$. While this might indicate an abundance of focus on curative care, it could also be attributed to incoherence amongst NSP and DHO office. Immunization and LHW program, the two programs with community health workers ( $\mathrm{CHWs}$ ) having responsibility for outreach vaccination of children, fell in the domain of DHO office. These $\mathrm{CHWs}$ despite being assigned to the contracted out healthcare facilities were not in a reporting relationship with NSP and hence not accountable.

While majority of the published literature including from Pakistan has focused on contracting out of primary healthcare facilities $(22,24,26)$, this study has assessed both primary and secondary healthcare facilities. Present study shows that most of the improvement in service utilization, health workforce, drugs, equipment and supplies and infrastructure is seen at secondary healthcare facilities. Being the only DHQH in the two districts, DHQH Thatta serves most volume of patients and probably the reason why it was the most invested in terms of resources. Attention was also given to improving surgical care in secondary hospitals, an important yet neglected area. Recent studies have reported serious shortage of surgeons and the availability and access to surgical care specially in rural areas (27). Though given the limited number of hospitals, surgical services provided may not be adequate to meet the needs of 2 million population, it certainly is a step in the right direction.

Present study assessed healthcare facilities from two rural districts i.e. Thatta and Sujawal. Following administrative division, Sujawal inherited majority of the rural population with health indicators relatively 
worse compared to Thatta (28). Present study also showed that healthcare facilities of Sujawal district were relatively understaffed compared to Thatta and hence were in need of attention.

Contrary to what is reported in literature (29) present study showed that clients didn't have to pay user charges to avail services of the healthcare facilities. However, availability of medicine was reported as a major issue.

\section{Strengths and limitations}

Present study had some methodological limitations. Data on KPIs was extracted using existing DHIS instead of active data collection. While it is not possible to comment on the quality of data, the validation of data was performed by evaluation team through health facilities survey and field verification to ensure consistency.

Present study used baseline data to measure the improvement in service utilization. The study used mixed methodology to perform a comprehensive assessment. Data from client exit interviews, IDIs with health managers and KPIs was corroborated to validate the findings.

An important strength of the study is that it has reported impact of contracting out from two rural districts of Sindh Pakistan including all of its primary and secondary public sector healthcare facilities. However, given the rural context, results may not be generalizable to all settings.

The study has evaluated process outcomes and utilization of services hence it is not possible to comment on the quality of health services and their impact on population health. Due to lack of baseline data, some components e.g. bed capacity, drugs, equipment and infrastructure could be assessed for adequacy only.

\section{Conclusion}

Contracting out has the potential to improve service utilization in remote rural settings in Pakistan. However, contracting out without transfer of complete autonomy related to budget release and control over government appointed health workforce can limit the contracting out model from achieving desired results on some frontiers. Lack of incoherence among stakeholders can result in issues such as delayed and partial release of budget, shortage of skilled workforce and staff retention. There is greater need to focus on improving immunization service and requires better coordination among different stakeholders with clear reporting lines.

\section{Abbreviations}

NGO: Non-governmental organization; NSP: Non-state provider; PPHI: People's Primary Healthcare Initiative; BHU: Basic health units; PPP: Public-private partnership; KPIs: Key performance indicators; RHC: Rural health center; THQH: Taluka headquarter hospital; DHQH: District headquarter hospital; MMR: 
Maternal mortality ratio; NMR: Neonatal mortality ratio; DHIS: District health information system; IDIs: Indepth interview; OPD: Out-patient department; ANC: Antenatal care; PNC: Post-natal care; LHW: Lady health workers; DHO: District health office; MLO: Medico-legal officer; CHWs: Community health workers;

\section{Declarations}

\section{Ethics approval and consent to participate}

Ethics Review Committee of the Aga Khan University Karachi Pakistan provided ethical approval for the study. All participants were invited and informed about the purpose of study, research design, and the uses of data. All participants provided written consent before participating in the study.

\section{Consent for publication}

Not applicable

\section{Availability of data and materials}

All data generated or analyzed during this study are included in this published article

\section{Competing interests}

The authors declare that they have no competing interests.

\section{Funding}

This work was supported by a grant from Medical Emergency Resilience Foundation [grant number 51761]

\section{Authors' contributions}

Imran Naeem Abbasi (INA) and Zafar Fatmi (ZF) conceptualized the idea. INA developed tools and ZF reviewed and amended. INA conducted and supervised the process of data collection and did analysis. INA wrote and revised the manuscript. ZF critically reviewed and provided feedback. All authors reviewed and approved the final draft of the manuscript.

\section{List Of Additional Files}

Additional file 1 - District wise breakdown of healthcare facilities

Additional file 2 - Key performance indicators (KPIs)

\section{References}


1. Odendaal WA, Ward K, Uneke J, Uro-Chukwu H, Chitama D, Balakrishna Y, et al. Contracting out to improve the use of clinical health services and health outcomes in low-and middle-income countries. Cochrane Database of Systematic Reviews. 2018(4).

2. Preker AS, Harding AL. Private participation in health services: The World Bank; 2003.

3. Palmer $\mathrm{N}$. The use of private-sector contracts for primary health care: theory, evidence and lessons for low-income and middle-income countries. Bulletin of the World Health Organization. 2000;78:8219.

4. Perrot J. Different approaches to contracting in health systems. Bulletin of the World Health Organization. 2006;84:859-66.

5. Loevinsohn B, Harding A. Buying results? Contracting for health service delivery in developing countries. The Lancet. 2005;366(9486):676-81.

6. Loevinsohn B, Harding A. Contracting for the delivery of community health services: a review of global experience. 2004.

7. Palmer N, Strong L, Wali A, Sondorp E. Contracting out health services in fragile states. Bmj. 2006;332(7543):718-21.

8. Siddiqi S, Masud TI, Sabri B. Contracting but not without caution: experience with outsourcing of health services in countries of the Eastern Mediterranean Region. Bull World Health Organ. 2006;84(11):867-75.

9. Health Department Government of Sindh Pakistan. Public Private Partnership Initiatives 2020 [cited 2020. Available from: https://www.sindhhealth.gov.pk/Partnerships.

10. Pakistan MoNHSRaC. Evaluation Peoples Primary Healthcare Initiative PPHI 20102010 [Available from: http://phkh.nhsrc.pk/knowledge-article/evaluation-peoples-primary-healthcare-initiative-pphi2010.

11. Health Department Government of Sindh Pakistan. Primary Healthcare Facilities 2020 [cited 2020. Available from: https://www.sindhhealth.gov.pk/Primary.

12. Health Department Government of Sindh Pakistan. Secondary Healthcare Facilities 2020 [cited 2020. Available from: https://www.sindhhealth.gov.pk/Secondary.

13. health Department Government of Sindh Pakistan. Tertiary Healthcare Facilities 2020 [cited 2020. Available from: https://www.sindhhealth.gov.pk/Tertiary.

14. Population of Bearu of Statistics Pakistan. PROVISIONAL SUMMARY RESULTS OF 6TH POPULATION AND HOUSING CENSUS-2017 2017 [Available from: http://www.pbs.gov.pk/content/provisional-summary-results-6th-population-and-housing-census2017-0.

15. World Health Organization. Maternal mortality in 1990-2015 2015 [cited 2020. Available from: https://www.who.int/gho/maternal_health/countries/pak.pdf?ua=1.

16. Pasha O, Saleem S, Ali S, Goudar SS, Garces A, Esamai F, et al. Maternal and newborn outcomes in Pakistan compared to other low and middle income countries in the Global Network's Maternal 
Newborn Health Registry: an active, community-based, pregnancy surveillance mechanism. Reproductive health. 2015;12(S2):S15.

17. UN Inter-agency Group for Child Mortality Estimation. Nonatal mortality rate Pakistan 2020 [cited 2020. Available from: https://childmortality.org/data/Pakistan.

18. World Health Organization. Service Availability and Readiness Assessment (SARA) 2013 [Available from: https://www.who.int/healthinfo/systems/SARA_Reference_Manual_Full.pdf.

19. The DHS Program. Quesionnaires and Modules 2020 [cited 2020. Available from: https://dhsprogram.com/What-We-Do/Questionnaires.cfm.

20. Zeng W, Sun D, Mphwanthe H, Huan T, Nam JE, Saint-Firmin P, et al. The impact and costeffectiveness of user fee exemption by contracting out essential health package services in Malawi. BMJ global health. 2019;4(2):e001286.

21. Baqui AH, Rosecrans AM, Williams EK, Agrawal PK, Ahmed S, Darmstadt GL, et al. NGO facilitation of a government community-based maternal and neonatal health programme in rural India: improvements in equity. Health policy and planning. 2008;23(4):234-43.

22. Vong S, Raven J, Newlands D. Internal contracting of health services in Cambodia: drivers for change and lessons learned after a decade of external contracting. BMC health services research. 2018;18(1):375.

23. Salehi AS, Saljuqi ATK, Akseer N, Rao K, Coe K. Factors influencing performance by contracted nonstate providers implementing a basic package of health services in Afghanistan. International journal for equity in health. 2018;17(1):128.

24. Maluka S. Contracting out non-state providers to provide primary healthcare services in Tanzania: perceptions of stakeholders. International Journal of Health Policy and Management. 2018;7(10):910.

25. Danel I, La Forgia G. Contracting for basic health care in rural Guatemala: comparison of the performance of three delivery models. Health Systems Innovations in Central America: Lessons and Impact of New Approaches. 2005:49-88.

26. Zaidi S, Riaz A, Rabbani F, Azam SI, Imran SN, Pradhan NA, et al. Can contracted out health facilities improve access, equity, and quality of maternal and newborn health services? Evidence from Pakistan. Health research policy and systems. 2015;13(1):S54.

27. Siddiqi S, Khan MS, Rizvi N, Naeem I, Rozi S, Enam A, et al. Are Rural Hospitals in Pakistan Responding to the Global Surgery Movement? An Analysis of the Gaps, Challenges and Opportunities. World Journal of Surgery. 2019:1-8.

28. United Nations Children Emergency Fund. Sindh Multiple Indicators Cluster Survey (MICS) 2014 [Available from: https://mics.unicef.org/news_entries/56/PAKISTAN-(SINDH)-2014-MICS-FINALREPORT-\&-DATASETS-RELEASED.

29. Riaz A, Zaidi S, Khowaja AR. Perceived barriers to utilizing maternal and neonatal health services in contracted-out versus government-managed health facilities in the rural districts of Pakistan. International journal of health policy and management. 2015;4(5):279. 


\section{Tables}

Table 1. Client exit interviews at healthcare facilities in Thatta and Sujawal $(\mathbf{N}=98)$

\begin{tabular}{|c|c|c|c|}
\hline & $\begin{array}{c}\text { Major problem } \\
\text { (\%) }\end{array}$ & $\begin{array}{l}\text { Minor problem } \\
\text { (\%) }\end{array}$ & $\begin{array}{l}\text { No Problem } \\
\text { (\%) }\end{array}$ \\
\hline Ability to discuss problems or concerns & 20.4 & 18.4 & 61.2 \\
\hline $\begin{array}{l}\text { Amount of explanation you received about the problem or } \\
\text { treatment }\end{array}$ & 23.5 & 22.4 & 54.1 \\
\hline Privacy from having others see the examination & 48 & 16.3 & 34.7 \\
\hline Privacy from having others hear your consultation discussion & 53.1 & 16.3 & 30.6 \\
\hline Availability of medicines at this facility & 64.3 & 17.3 & 18.3 \\
\hline The hours of service at this facility i.e. when they open and close & 13.3 & 30.6 & 56.1 \\
\hline The number of days services are available to you & 9.2 & 31.6 & 59.2 \\
\hline The cleanliness of the facility & 35.7 & 28.6 & 35.7 \\
\hline How the staff treat you & 27.6 & 13.3 & 59.2 \\
\hline Costs for services or treatments & 13.3 & 28.6 & 58.1 \\
\hline
\end{tabular}

Figures 

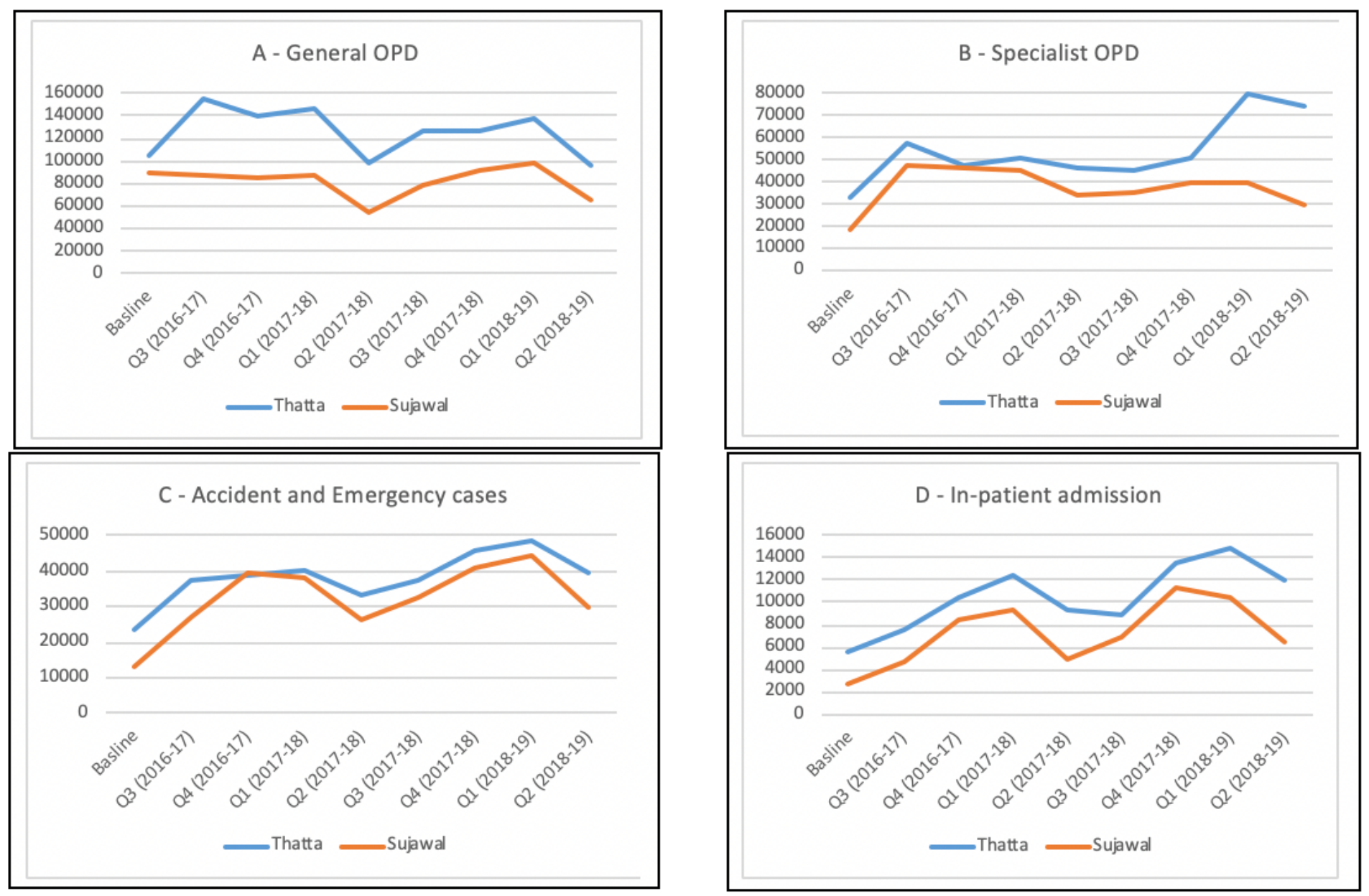

\section{Figure 1}

Trends of out-patient (OPD) consultations and inpatient admissions in Thatta and Sujawal districts during contracting out period
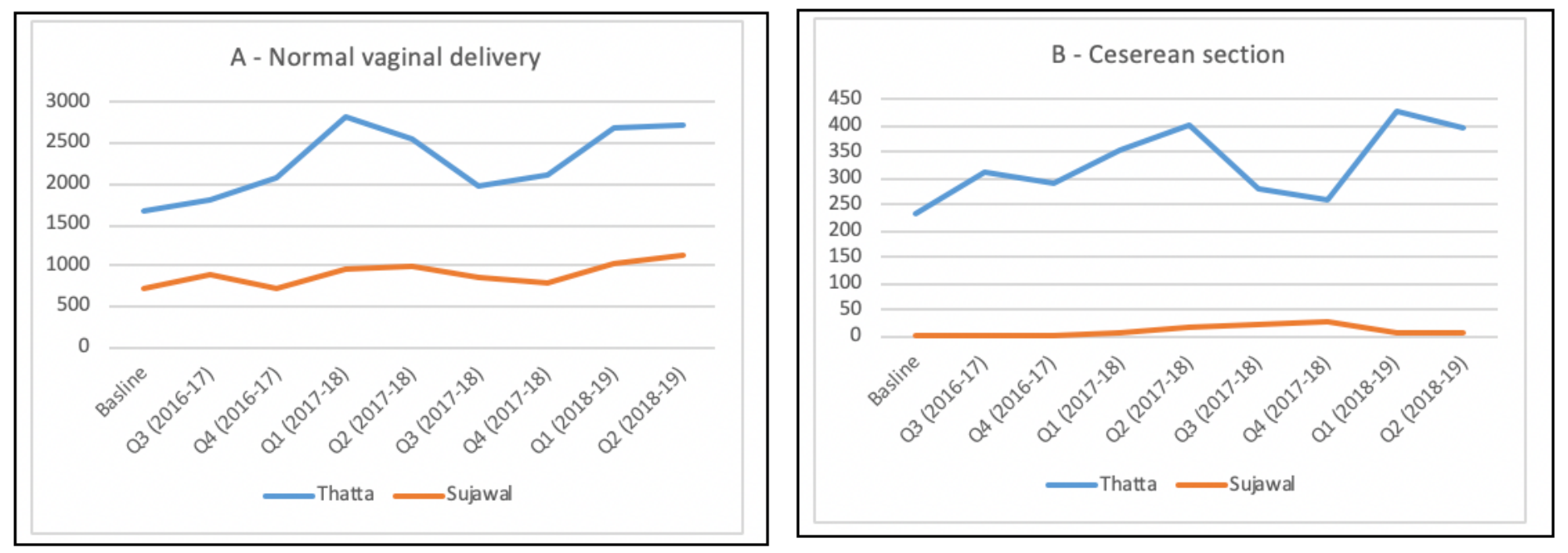

Figure 2 
Trends of institutional deliveries (normal vaginal and cesarean section) in Thatta and Sujawal districts during contracting out period

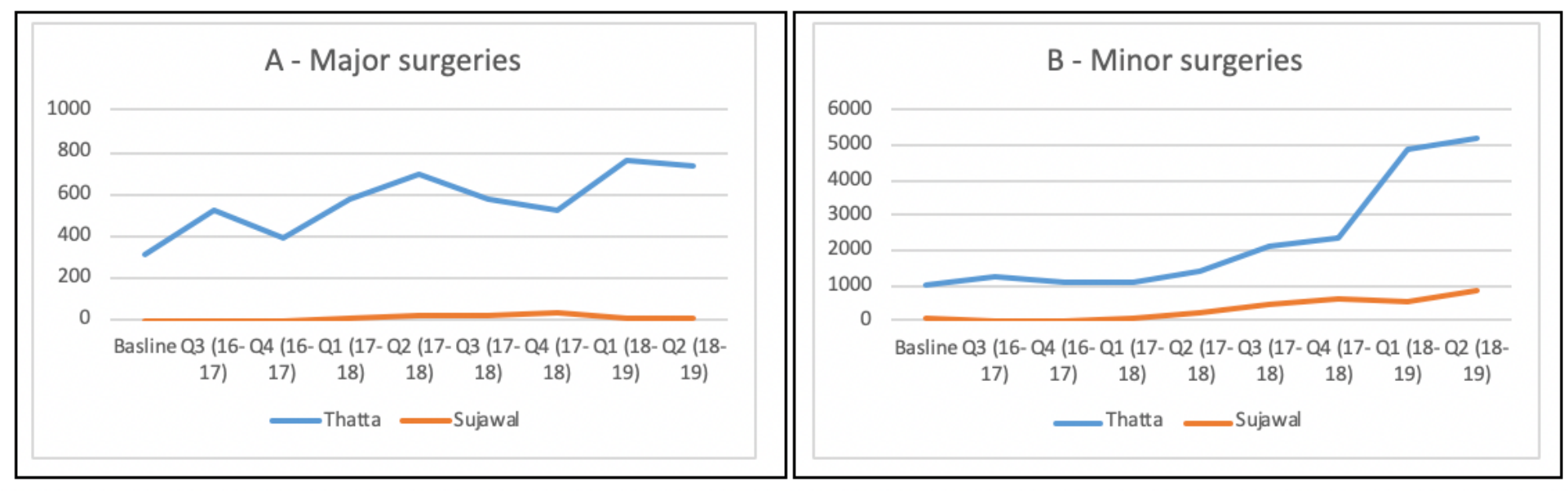

\section{Figure 3}

Trends in major and minor surgeries in Thatta and Sujawal districts during contracting out period
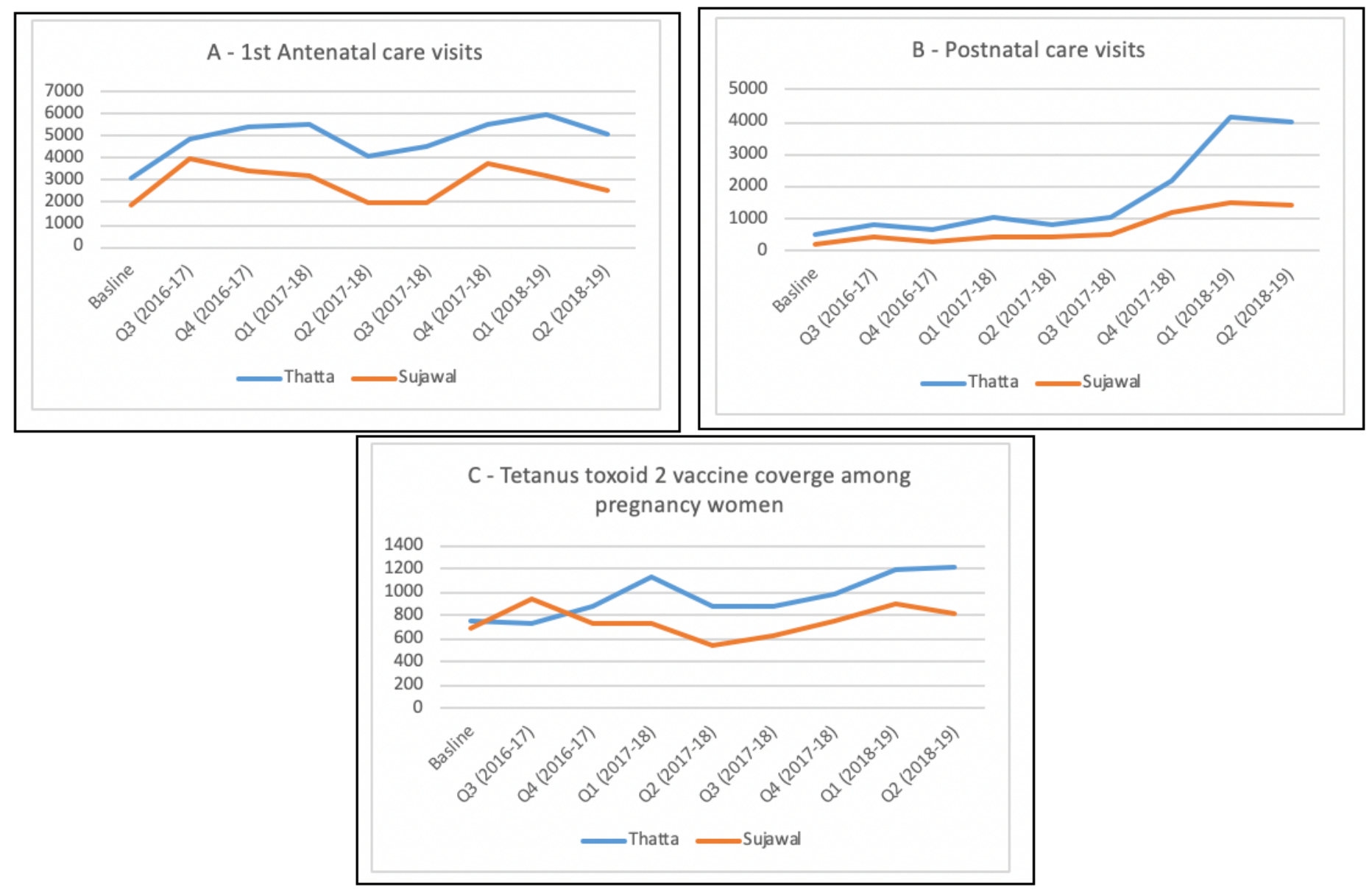

Figure 4

Trends in major and minor surgeries in Thatta and Sujawal districts during contracting out period 

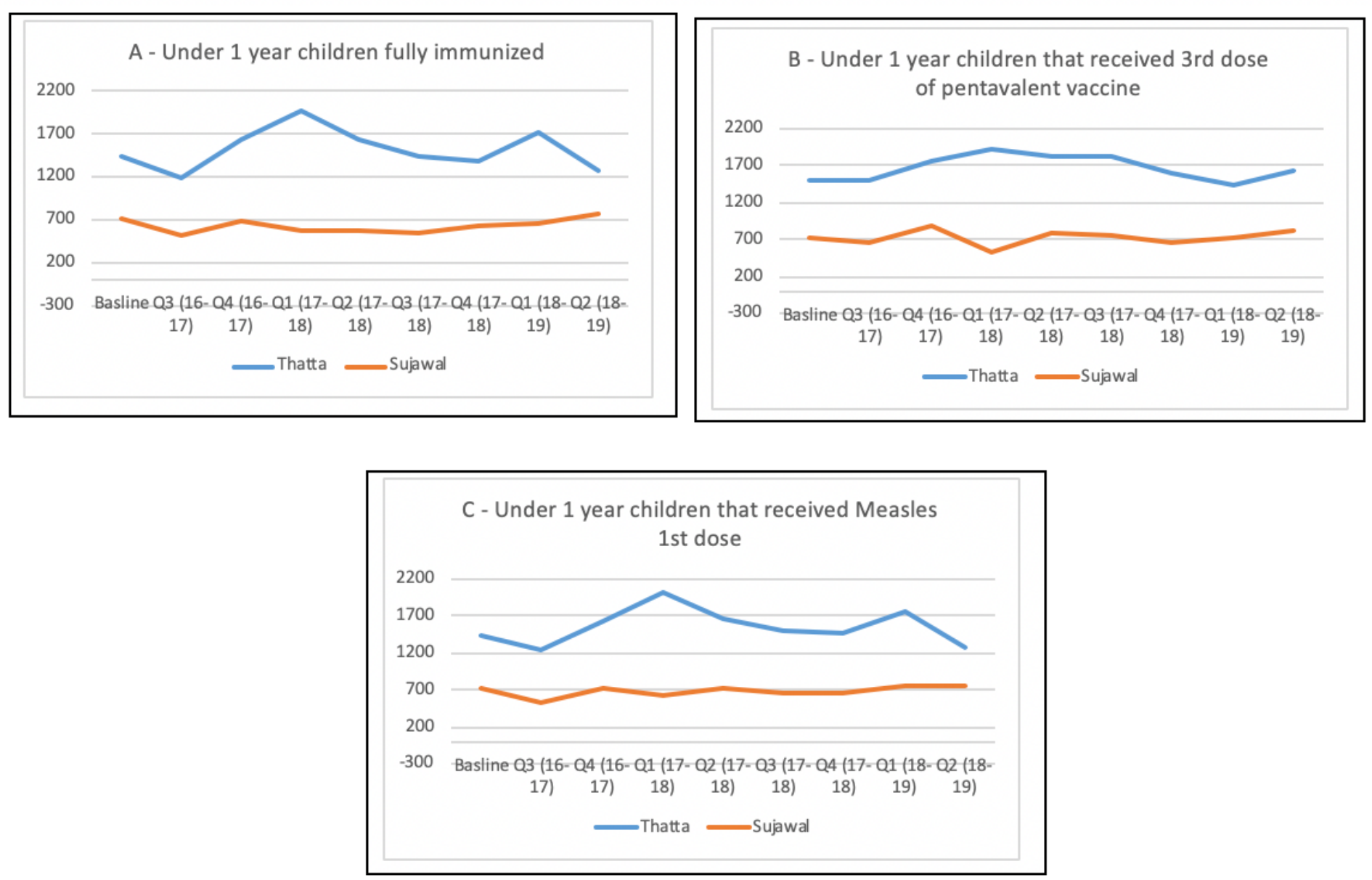

Figure 5

Trends in immunization for children under 1 year of age in Thatta and Sujawal districts during contracting out period

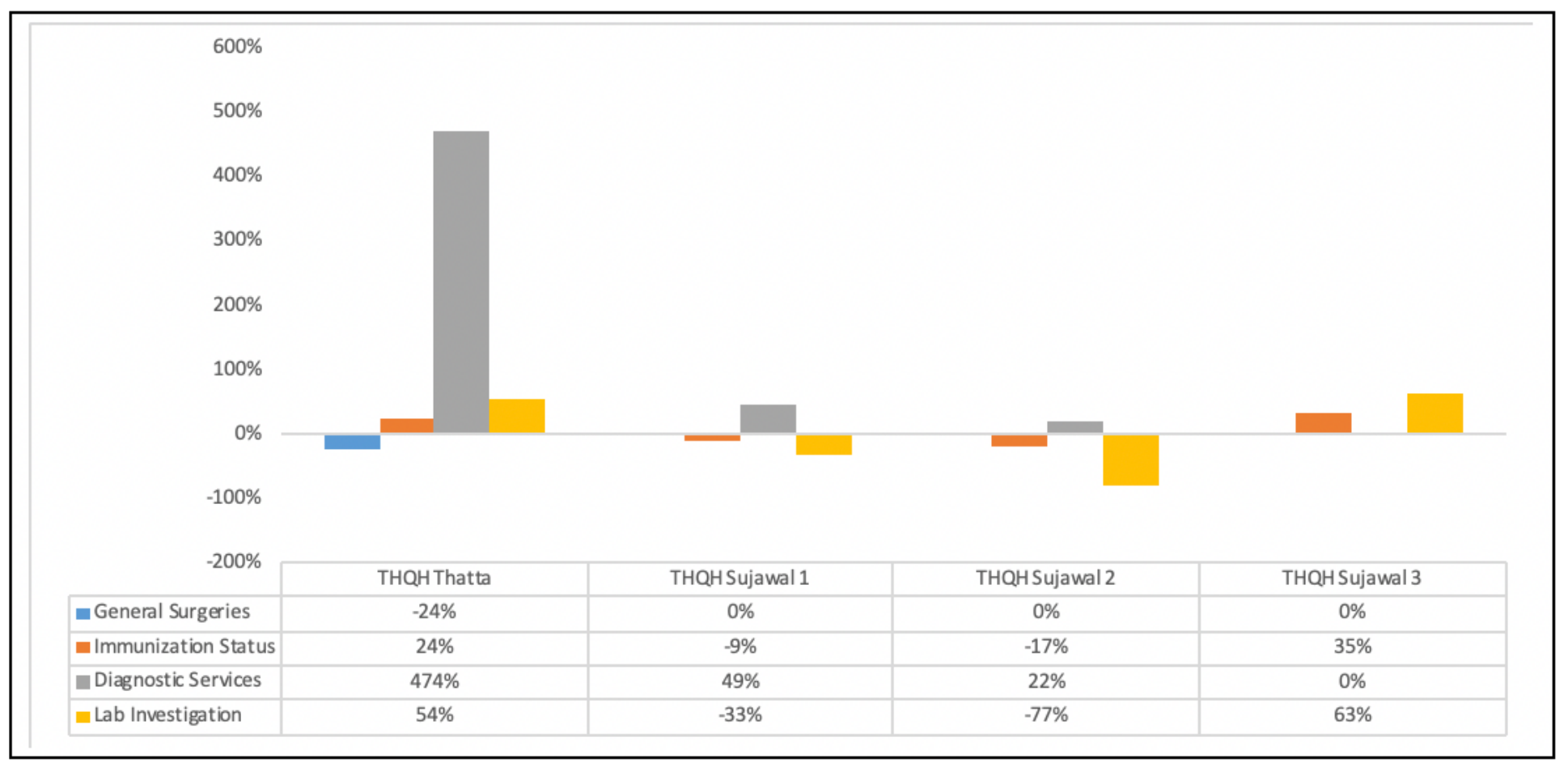


Figure 6

Change in KPIs at THQHs of Thatta and Sujawal districts

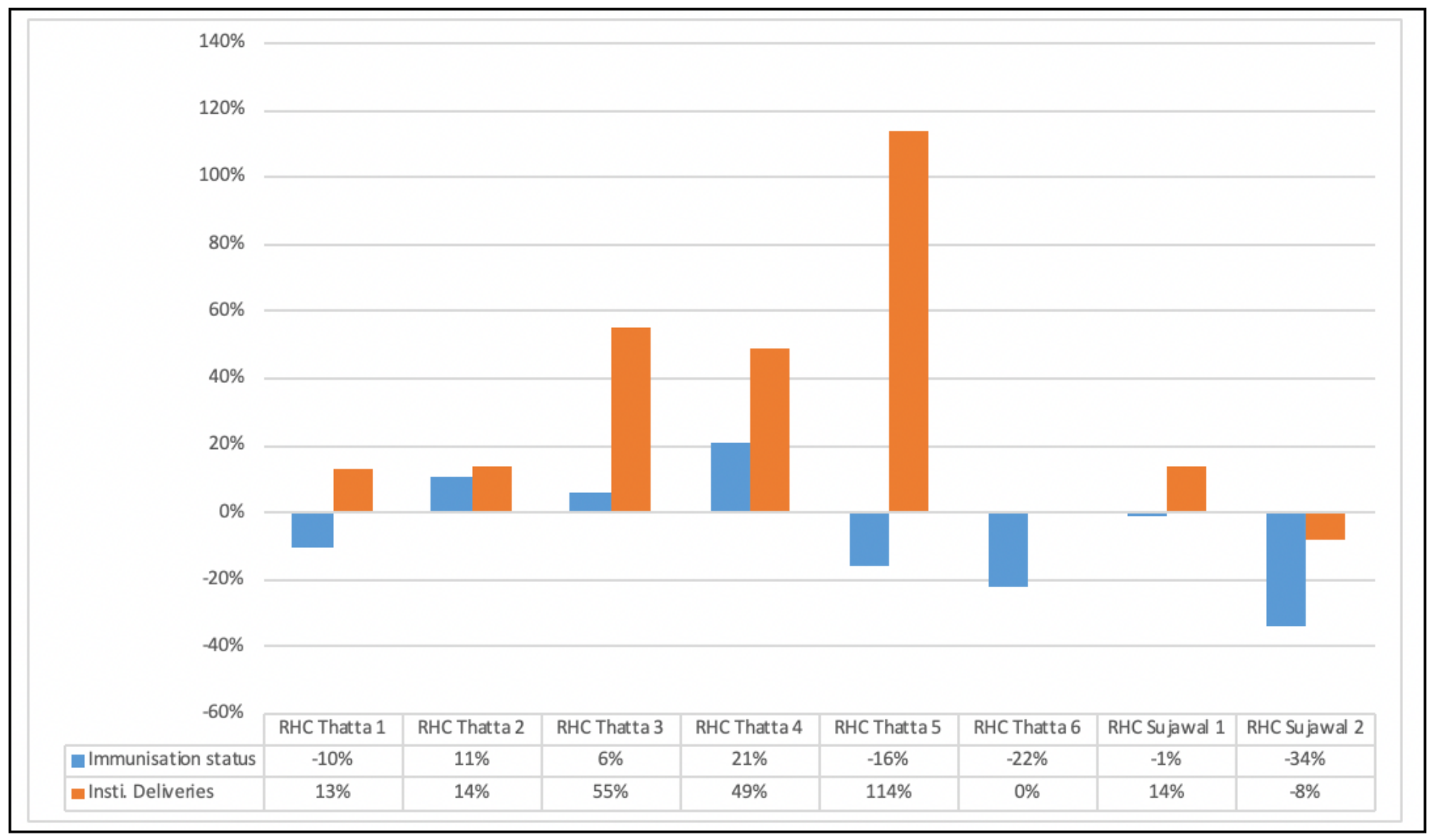

\section{Figure 7}

Change in status of institutional deliveries \& immunization coverage of RHCs 


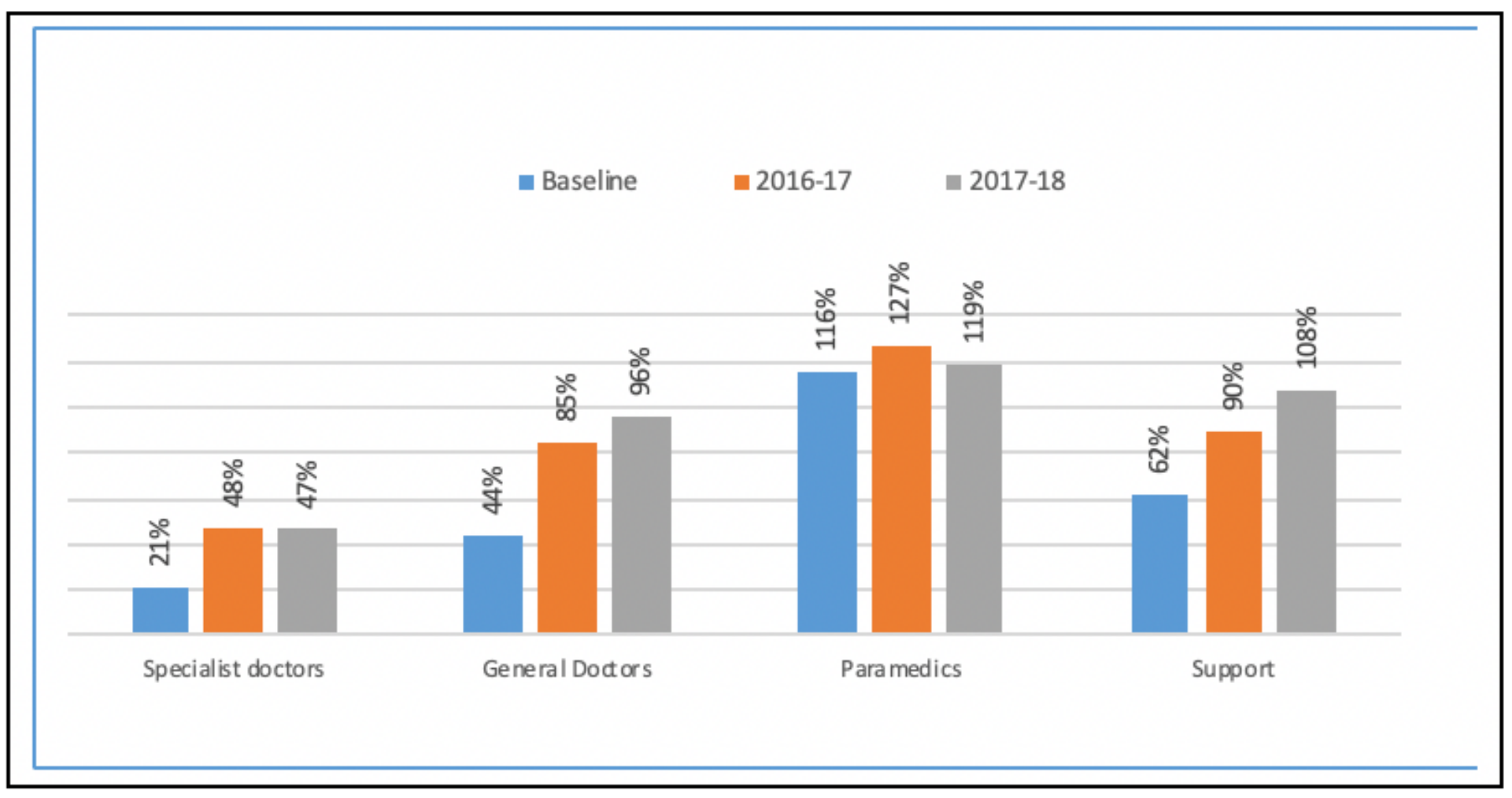

Figure 8

Change in staffing situation of healthcare facilities in Thatta and Sujawal districts during contracting out period

\section{Supplementary Files}

This is a list of supplementary files associated with this preprint. Click to download.

- Additionalfile1.docx 